\title{
AUTORRETRATO FEMININO: UMA LEITURA FILOSÓFICA DO ROMANCE "JORNADA DIABÓLICA" DE KATHLEEN WINSOR
}

\author{
Henderson Bueno Marchiorato'
}

\begin{abstract}
RESUMO: Atualmente a significação social das mulheres vem sendo mundialmente tema para inumeráveis exposições literárias, desde trabalhos acadêmicos até poesias marginais. Contudo, pensamos existir um nicho particularmente ignorado sobre o assunto: trata-se da literatura romanceada menor, de pouco destaque pela crítica literária, ainda desconhecida do público e que desenvolva a trama tendo a mulher ou a feminilidade como temática central. Mais que isso, tratase desta literatura preferencialmente segundo a produção por parte de escritoras mulheres. Assim, o objeto deste artigo é o romance da escritora estadunidense Kathleen Winsor intitulado Jornada Diabólica, onde apresenta o mundo feminino em meados do século XX por meio de uma narrativa ficcional. A maneira como abordaremos este objeto será guiada, com a ajuda de alguns pensadores contemporâneos, pela interpretação filosófica dos principais pontos componentes do romance, que pode ser sintetizado como um triangulo amoroso que se passa no inferno. O caráter fantasioso do enredo não nega ou esvazia o sentido realístico que o ser-mulher é trabalhado pela autora; pelo contrário, a metaforização que estabelece o inferno como a região em que tudo acontece representa um artificio literário aproximativo da ideia de inferno ao contexto real. Ou seja: entre a realidade terrena e o inferno há muitas semelhanças, principalmente concernente ao papel da mulher. O principal objetivo deste texto é desenvolver pela argumentação filosófica a verticalização de uma obra aparentemente desimportante, assim demonstrando que mesmo a literatura fantástica de pouca expressão tem muito a contribuir sobre temas atuais, como o caso da performance social da mulher.
\end{abstract}

PALAVRAS-CHAVE: Filosofia. Literatura Fantástica. Interdisciplinaridade. Winsor. Mulher.

\section{INTRODUÇÃO}

"neste mundo, segundo opiniões abalizadas, e seguidas, uma mulher já faz muito quando consegue ser bonita" - Cecília Meireles (1998, p. 228).

O ainda não explorado romance Jornada Diabólica [On Roaring Mountain by Lemonade Lake], publicado em 1952 como uma das três estórias que compõem o livro As Amorosas [The Lovers], da escritora norte-americana Kathleen Winsor (1919-2003), autora do best-seller posteriormente adaptado para o cinema com o título Entre o Amor e o Pecado [Forever Amber], podia muito bem ser temática de análises filosóficas, principalmente aquelas de teor existencialista. É bastante provável que a Psicologia, principalmente as linhas com viés psicanalítico, represente também uma alternativa de lançar luz sobre esta curiosa

\footnotetext{
${ }^{1}$ Graduado em Filosofia pela Pontifícia Universidade Católica do Paraná, PUC/PR, Brasil. Email: henderson.gvtnovatele@gmail.com
}

Revista de Letras JUÇARA, Caxias - Maranhão, v. 02, n. 01, p. 224 - 243, jul. 2018| 224 
obra. Sua escrita sinuosa ora interpela questões ligadas ao desejo e a sexualidade, ora questões próximas à sublimação e o mecanismo repressor, sem, contudo, se ater verticalmente sobre estes pontos.

Talvez seja essa esquiva, proposital ou não, o grande trunfo da literatura frente os textos técnicos, porquanto abre possibilidades de interpretação que escapam a qualquer conceituação, terminologia ou sistematização unicamente teorética. Esta abertura interpretativa permite o acesso do leitor a lugares desconhecidos do campo científico, mesmo estes lugares sendo de extrema importância no contexto pessoal ou social.

Mas, poder-se-ia perguntar, o que a literatura não técnica, neste caso o romance Jornada Diabólica, enquanto uma manifestação não científica sobre a experiência feminina, pode nos oferecer objetivamente sobre a realidade da mulher moderna? É o que se pretende responder neste ensaio filosófico². Por isso, se quisermos prezar pela fidelidade as valiosas demandas que o texto de Winsor suscita, precisamos usar de ferramentas interdisciplinares; por isso nosso aporte na filosofia, pois esta não é outa coisa senão a arte do dialogo. Evidenciar paralelos interdisciplinares entre literatura e filosofia, construir uma ponte que ligue estes dois campos superficialmente tidos como distintos - eis nossa tarefa.

É antes uma análise filosófica que uma análise técnica, científica, ortodoxa o que aqui pretendemos elaborar sobre um texto de literatura fantástica. Nesse sentido, nossa interpretação intentará encontrar nesta estória singular um senso comum que permita uma reflexão hermenêutica sobre o papel da mulher tematizado no romance. Tudo isto sem recalcar e desrespeitar o sentido leve e despretensioso que uma literatura romanceada oferece. ${ }^{3}$ Tais considerações são necessárias para não cometermos o erro corriqueiro, todavia execrável e

\footnotetext{
${ }^{2}$ Com a genérica denominação "ensaio filosófico" queremos mais negar uma tipificação como "resenha crítica" ou "artigo científico" do que realmente afirmar uma categoria de escrita. Pode-se dizer pedagogicamente que este texto se encontra a meio caminho entre uma resenha e um artigo eminentemente científico. Trata-se simplesmente de uma interpretação filosófica acerca de uma obra de literatura ficcional e romântica.

${ }^{3}$ Como um modo adequado que permita tanto salvaguardar o rigor interpretativo quanto a linguagem fluida característica de romances literários, optamos por citar diretamente algumas passagens da obra. As passagens que serão discutidas se encontraram no corpo do texto, as passagens que servirão mais como um referencial interpretativo se encontrarão em notas de pé de página.
}

Revista de Letras JUÇARA, Caxias - Maranhão, v. 02, n. 01, p. 224 - 243, jul. 2018| 225 
infundado, de basearmos nossa crítica em critérios estritamente técnicos, abstratos, literários, artificiais. ${ }^{4}$

\section{ACERCA DO ENREDO E TRAMA}

Feito essa importante ressalva metodológica, pensamos ser adequado antes de mais realizarmos um comentário introdutório e sucinto sobre o conteúdo textual do romance. Pois bem: a estória majoritariamente tem seu enredo dirigido estilisticamente em terceira pessoa, embora diversas vezes na voz da personagem protagonista, isto é, na primeira pessoa. $\mathrm{O}$ ambiente em que se desenrola toda narrativa é o inferno, posto em conhecimento do leitor logo no início do romance. É nesse mundo ermo, opaco, sufocante - embora rodeado de belezas exóticas - que muitas intrigas amorosas, expostas em cenas tragicômicas, são embebidas nas sutilezas de uma literatura, a um só tempo, profunda e rasa, dando impressão ao leitor de que tal estória carrega certo misterium entre as linhas que se seguem gostosamente. Mesmo que recheado de descrições paisagísticas, é interessante notar que a autora não se atém muito aos detalhes da paisagem quanto aos detalhes emocionais que as situações instigam, revelando a primazia de seus esforços literários na construção de imagens que adequadamente apontem para as sensações da alma, se quiser, aos aspectos psicológicos e emocionais dos personagens. Como veremos detalhadamente no percurso deste ensaio, o que perpassa de ponta a ponta a obra Jornada Diabólica é um jogo que ocorre no espírito feminino entre temporalidade, desejo e autorrepresentação, ou seja, um jogo introspectivo que projeta sentido desde a

\footnotetext{
${ }^{4}$ A filósofa norte-americana e militante do feminismo Robin Schott analisa em seu livro Eros e os Processos Cognitivos como a manifestação erótica foi abolida do campo epistemológico em que a filosofia atua. Mais que isso, a autora afirma que esta abolição prejudicou a participação da mulher no labor filosófico, pois conjuntamente com este preconceito epistemológico uma orientação sexista que considera o sexo feminino como sensível, apaixonado, erótico acaba por renegar estes atributos construídos tipicamente como próprios da feminilidade. A mulher não é dotada de autocontrole, logo não é naturalmente propicia para o filosofar. À guisa de ilustração: "O paradigma filosófico da objetividade não apenas acarreta uma operação por parte de pensadores objetivos que devem destituir-se de sua existência sensual, mas tem também implicações sociais mais amplas. Esse ideal filosófico tem historicamente justificado a exclusão das mulheres de instituições de educação superior, que servem como avenidas para o poder social, e de outros domínios da atividade pública para as quais as mulheres tem sido consideradas insuficientemente racionais." (SCHOTT, 1996, p. 11). Com base neste argumento, preferimos preservar o clima não objetivo da obra literária que nos propomos investigar.
} 
intimidade de uma personagem mulher até a realidade externa por ela vivenciada no inferno.

Mas continuemos a introdução à obra. Embora seja um romance muito rico, marcado por uma ambiguidade que mescla literatura fantástica e realista, a estória conta apenas com poucos atuantes. A protagonista da obra chama-se Jacinta Frost, uma jovem vitoriana contando vinte e cinco anos; além dela, temos outros dois personagens de destaque: Cherry Anson, também com vinte e cinco anos, mãe de Jacinta, e o Diabo. Além destes, temos outras duas personagens secundárias, ambos servidores, a saber, a camareira Beth e o chofer Grant. Assim, toda a obra basicamente gira em torno dessas cinco personagens. $\mathrm{Na}$ verdade, é só o triangulo amoroso composto por Jacinta, Cherry e o Diabo que tem importância no texto. Em essência, trata-se, como já dito, de um triangulo amoroso entre mãe, filha e o Diabo que se passa no inferno. Por fim, nenhuma das duas personagens consegue persuadir a escolha do Diabo, de forma que ele mantem as duas a sua disposição.

São tão-somente em sete cenários que quase toda a trama é desenvolvida. Apesar de o romance ocupar mais de cento e setenta páginas, os lugares em que tudo acontece são poucos, assim como os dias — apenas três. $\mathrm{Na}$ realidade, quase metade da estória se passa no dormitório de Jacinta. É importante esta ressalva porque este aspecto minimalista demonstra que 0 interesse principal da autora está concentrado nos conflitos internos que transpassam o ser de Jacinta, pois são nestes momentos de intimidade reflexiva que aparecem destacados os pontos mais importantes da trama, principalmente a questão da autorrepresentação desde o reconhecimento do outro. ${ }^{5}$

A protagonista está no inferno porque traiu seu marido, Martin; e este matou-a após descobrir a infidelidade com um disparo de um revolver. Isto explica

\footnotetext{
${ }^{5}$ Aqui devemos lembrar o leitor de que esta questão da apercepção de si mesmo a partir do olhar de um outro foi primorosamente trabalhada por Jean-Paul Sartre (1905-1980) em diversas obras, tanto filosóficas como literárias e teatrais. Porém, como o romance de Winsor trata de uma apercepção feminina, além de ser ela mesma uma mulher, portanto conhece o que diz por experiência, pensamos ser ainda mais importante lembrarmos o nome de Simone de Beauvoir (1908-1986), pois foi esta quem pela primeira vez explorou minuciosamente o papel que a mulher tem na sociedade e como este papel provém de uma autorrepresentação como sexo inferior, secundário e frágil. Além disso, é importante frisar que tanto Kathleen Winsor como Simone de Beauvoir conviveram sob os costumes da sociedade de meados do século passado; Beauvoir até chegou a morar nos Estados Unidos. Seria de extrema importância uma análise que relacionasse os pontos convergentes entre as investigações de uma filósofa e as narrativas de uma escritora de romances.
} 
como ela morreu, mas não explica porque ela foi para o inferno e não para o paraíso. É que, segundo a explicação dada pelo próprio Diabo, as pessoas são enviadas para o inferno conforme o juízo dos indivíduos próximos contemporâneos. Como a infidelidade feminina era tachada moralmente como uma conduta desprezível, os julgamentos tenderam a pensar que sua morte fora uma consequência senão correta pelo menos merecida. ${ }^{6}$

\section{TEMPORALIDADE E DESEJO}

Eis a situação em que Jacinta se encontra no inferno. Mas, que é o inferno? Isto é, qual sua diferença fundamental, sua peculiaridade, sua característica inerente sem a qual já não pode ser identificado como inferno? Sempre conforme o que está expresso no livro, podemos facilmente apontar algumas facetas desse mundo em que a estória se passa. Referimo-nos a imoralidade, a paisagem, a coexistência de pessoas de varias épocas, os fenômenos sobrenaturais, a hiper-superficialidade das relações, a solidão, o tédio, entre outras. Todas, entretanto, remetem a algo mais essencial, algo que participa de todas essas facetas citadas sem, contudo, se fixar numa delas para existir. É como que o pano de fundo por trás do inferno. Refiro-me a temporalidade.

Se nos ativermos para esse "detalhe", veremos que não se trata de modo algum de um detalhe. Pois o que faticamente determina a diferença ontológica entre a vida antes do inferno e durante o inferno é o tempo. A realidade anteriormente, na vida como conhecemos, era subordinada por um modo específico de se relacionar com o tempo, por uma dinâmica própria que contempla passado, presente e futuro, pela finitude de uma existência que pode findar a qualquer momento, que se percebe limitada pelo tempo, que envelhece, tendo como única certeza aquilo que não pode escapar: a morte. As teorias do filósofo alemão Martin Heidegger (1889-1976) sobre a finitude humana, expressas em seu livro Ser e Tempo - considerada por muitos a obra de filosofia mais influente do século $X X$-, indicam a importância que a temporalidade assume na existência humana. Segundo este viés, a vida de um indivíduo é condicionada

\footnotetext{
${ }^{6}$ Este ponto, sobre a recriminação social da infidelidade feminina, assim como muitos outros que a autora propõe, em muito nos são conhecidos pela experiência cotidiana. Ao final deste ensaio retornaremos a estes pontos em que para nós são atualíssimos.
} 
pelo incondicional. No inferno, a existência não segue as mesmas condições. A existência é condicionada pela eternidade: já não há morte, fome, medo da morte, doenças, sonhos, ou qualquer outra necessidade existencial e material que interpele e afronte a luta pela sobrevivência. De um lado a vida é moldada pela necessidade imposta pela finitude temporal, do outro é moldada pela liberdade imposta pela infinitude do tempo.

Não resta muita coisa a se fazer no inferno senão desfrutar desta liberdade plena. Porém, a autora coloca esta liberdade plena como um empecilho para uma existência bem aproveitada. ${ }^{7}$ Em certo momento Winsor (1987, p. 93) escreve: "Pode-se fazer o que se tem vontade. Não há regulamentos", e arremata escrevendo: "Com o tempo, a gente descobre que, não havendo nada obrigatório, não há nada que se queira fazer", mostrando que as obrigações são partes fundamentais do que se chama comumente de bem-viver. Afinal, mesmo que existisse uma liberdade plena para se gozar a existência, o próprio sentido e intensidade deste gozo seria reduzido, talvez ao ponto de tudo perder a graça, caso não houvesse limitações de qualquer estirpe. Já Sigmund Freud (18561939) descobriu que o chamado "interdito", a negação dos desejos inconscientes primevos, ajudam a potencializar o desejo na medida em que é algo proibido, melhor dizendo, algo que está além de nossa liberdade.

No entanto, aqui nos deparamos com duas possibilidades diferentes de compreender aquilo que está além de nossa liberdade. Uma significa proibição, bloqueio, barreira. Este se assemelha mais ao sentido em que opera a psicanálise freudiana. Outra possibilidade de interpretação versa sobre as ocupações necessárias, as obrigatoriedades, compromissos rotineiros, responsabilidades inescusáveis. Exemplificando, é bastante diversa uma situação em que a mulher é impedida pelo marido de trabalhar fora de uma situação em que uma mulher

\footnotetext{
${ }^{7}$ A escritora deposita as seguintes palavras no discurso proferido pelo personagem representante do Diabo, o senhor daquele reino: "O problema aqui é de excesso de lazer e nos cabe a cada um resolve-lo da melhor forma possível. Você precisará encontrar os meio que puder para passar a eternidade. Pode considerar a ideia, e é bom que o faça, como um desafio, um teste de imaginação e expediente. Não quero ser pessimista, mas estou aqui há muito e deduzo da minha própria experiência, além do que tenho ouvido de outrem, que é impossível triunfar ao desafio. Tudo aqui é muito agradável; estou certo de que concorda - ele gesticulou para mostrar a decoração luxuosa do aposento -, todos, porém, vivem descontentes, inclusive eu. Verdade é que qualquer paraíso transforma-se em inferno quando dura muito" (WINSOR, 1987, p. 132-133).
} 
tem que trabalhar fora para sustentar seus filhos ${ }^{8}$. Em comum, ambos têm 0 caráter de limitação da liberdade: de um lado a limitação surge de alguém ou algo que está impedindo um desejo de se realizar, de outro a limitação brota de uma situação que demanda um determinado uso da liberdade. É uma questão de poder e dever.

O que interessa nisso tudo é que o desejo surge de uma limitação, seja no sentido negativo que diz "não deve-se fazer isso!" ou no sentido positivo que diz "deve-se fazer isso!". O querer, paradoxalmente, parece na maioria das vezes ir contra estas limitações: geralmente queremos fazer aquilo que é proibido ser feito assim como não queremos fazer aquilo que é mandatário ser feito. Mas, como notou Winsor, somente com o tempo damo-nos conta de que a liberdade só pode ser plenamente desfrutada quando de alguma maneira é limitada. Neste sentido, a temporalidade infinita não sugere, como numa primeira impressão pode parecer, uma liberdade infinita e, consequentemente, um desfrute infinito, porquanto não há limitação temporal. A escritora, através das palavras da personagem Cherry, afirma que o clima do inferno não é agradável. "Isto aqui é muito desolado. A muita gente e muito movimento e, no entanto, a gente sente-se sempre solitária. Talvez seja a falta de objetivo ou a certeza da eternidade" (WINSOR, 1987, p. 37). Por se saber que tudo estará disponível eternamente, o humor prazenteiro que se manifesta quando temos acesso às novidades, ao desconhecido, ao diferente e as originalidades é mitigado ou mesmo neutralizado, sendo dominado por um humor tedioso, chato, maçante ou enjoativo. ${ }^{9}$

Embora a eternidade seja o horizonte, Cherry em certo momento diz que nunca explorou o inferno porque não teve tempo, mesmo estando ali há mais de vinte anos. Para esta ambiguidade, Cherry explica dizendo que o tempo passa

\footnotetext{
${ }^{8}$ Embora sejam manifestamente situações diversas, infelizmente é mais comum do que parece, pelo menos no contexto brasileiro, que estas duas situações aconteçam em um mesmo lar.

${ }^{9}$ Este sentimento desagradável de marasmo, em que nada parece despertar suficientemente o desejo, muitas vezes pode levar a busca de subterfúgios insensatos e meramente hedonistas capazes de proporcionar satisfação apenas momentânea a qualquer preço. Winsor escreve a respeito que "o perigo é um dos poucos antídotos que temos contra o tédio" (WINSOR, 1987, p. 102). Nos dias atuais temos incontáveis práticas perigosas que envolvem a fuga do tédio, como esportes radicais, o uso de drogas ilícitas, corridas automotivas ilegais (popularmente conhecidos como "pegas" ou "rachas"), vandalismos como pichações e brigas de gangues, além do adentramento na criminalidade organizada. Desde a psicanálise, talvez pudéssemos entender estas manifestações que acompanham perigos iminentes como sintomas de uma neurose social crônica que já não sabe administrar suas pulsões de maneira simbólica, de forma que as degradantes pulsões de morte prevalecem sobre as pulsões de vida.
} 
muito rápido ali. A autora não explica este paradoxo: como o tempo dá a sensação de passar simultaneamente rápido e devagar? Uma interpretação possível é que devido ao fato de não se ter afazeres obrigatórios com o que se ocupar, os habitantes sejam dominados por um clima de "tanto faz" que impede o acompanhamento regrado do passar do tempo. Deste modo, o tempo não é medido, por isso também não é percebido em sua duração ${ }^{10}$.

Além deste fator temporal, que nos faz pensar melhor sobre nossa mortalidade, nosso tempo-livre e nossas ocupações rotineiras, há também outro fator que merece ser destacado, a saber, o papel que o desejo assume no romance. Com efeito, a personagem principal, Jacinta Frost, desde o inicio se apaixona pelo Diabo. Porém não se trata de uma paixão comum, mas de um sentimento arrebatador a um só tempo fantasioso e real. Isto é possível se dermos a devida atenção para a função que o fetichismo estabelece neste desejar. O Diabo diz que todos o pintam como querem. O Diabo tem a aparência que projetam nele. Ora, por que então ele tem uma aparência tão máscula, energética, viril e bonita e não uma aparência desprezível e horrenda, como o senso comum sempre disserta? Resposta: porque o que se mais se despreza no Diabo é o caráter "tentador" que ele exerce sobre os pecadores. Neste sentido, para uma moça jovem, ardorosa e sensual como Jacinta, que foi para o inferno precisamente por recair a uma tentação sexual extraconjugal, é absolutamente coerente que o Diabo tenha uma aparência estética tentadora, isto é, que atraia involuntariamente e de forma arrebatadora o desejo de Jacinta.

\begin{abstract}
Jacinta acreditava, em virtude do rápido contato que haviam mantido, que ele era verdadeiramente capaz de despertar um apetite insaciável. . Porém, desde que uma mulher sucumbisse à força mesmérica de sua personalidade, ficaria à mercê de uma natureza inquieta, inteiramente sujeita ao próprio capricho, impiedoso, violento, arbitrário. Teria muito que temer e pouco que esperar. Volveria, como se a civilização houvera regredido ao nada, a uma servidão impotente, escrava integral da sua própria necessidade. Perderia a dignidade, a capacidade de recusar, qualidade que a mulher não pode prescindir para a sua própria proteção e para a sua sobrevivência decente. (WINSOR, 1987, p. 59).
\end{abstract}

\footnotetext{
10 Podemos entender isto facilmente se atermo-nos as nossas experiências pessoais. Muitas vezes, quando não temos o que fazer (nos domingos, por exemplo) somos transpassados pelo tédio ao mesmo tempo em que nem notamos que as horas estão passando, de forma que quando nos deparamos o dia já acabou e não fizemos absolutamente nada. Parece ser isto o que Cherry quis dizer quando diz que não fez muita coisa em vinte anos, mesmo tendo tempo de sobra para isso.
}

Revista de Letras JUÇARA, Caxias - Maranhão, v. 02, n. 01, p. 224 - 243, jul. 2018 | 231 
Jacinta se encontra em um beco sem saída. O desejo é irresistível; e com essa irresistibilidade surge a insegurança feminina de, simultaneamente, ser considerada indigna deste desejo devido sua própria natureza (aparência, inteligência, "jeito de ser"), logo recusada por parte daquele de que se esta apaixonada, como de ser considerada demasiadamente promiscua, isto é, estar fora dos padrões morais referentes às relações de desejos sensuais, também podendo ser ignorada por isso. Porém, é sobretudo pela perda do autocontrole que o Diabo exerce sobre ela que Jacinta sente-se insegura, inquieta, desconfortável. ${ }^{11}$ Ela percebe-se indefesa diante da presença implacavelmente sedutora do Diabo, sujeita a seus manejos, sua volição, seu alvitre. Neste sentido, nada mais consequente que no espírito de Jacinta um turbilhão de sentimentos confusos, senão contraditórios, dilacerem sua consciência deliberativa. Ela deseja o Diabo, não há dúvida; mas também deseja não desejá-lo.

Se existisse a possibilidade de escolha, as opções seriam: 1) ela despojar-se do orgulho pessoal e deixar-se sucumbir aos seus desejos pelo Diabo; 2) ela negar seus desejos e manter o autocontrole; 3) buscar um meiotermo entre as duas opções anteriores. Nos três modos ela sairá insatisfeita. No primeiro caso ela perderia seu autocontrole, no segundo caso ela teria de conviver com desejos reprimidos e no terceiro caso ela permaneceria no estado de perturbação emocional em que se encontra.

Além deste aspecto, Winsor chamou atenção também para a dignidade feminina. A escritora dá a entender que a dignidade da mulher consiste em sua capacidade de recusar. Entretanto não é somente da recusa das inclinações masculinas de que a autora esta falando, mas principalmente das próprias inclinações. Com efeito, dentro do contexto exposto, trata-se da capacidade de recusa e não do ato de recusar propriamente dito; esta capacidade só é afetada e fragilizada quando a mulher perde o autodomínio sobre seus desejos. Assim, no caso de Jacinta, ela já não detém o poder sobre esta capacidade de recusa, de

\footnotetext{
${ }^{11}$ Numa passagem esclarecedora, Winsor descreve o turbilhão emocional que se passava no espírito de Jacinta: "Deixa-me desamparada e incompleta; reduz-me a uma fêmea que segue o macho onde quer que vá, transportando um pesado fardo. O fardo é o meu próprio desejo, que não consigo evitar. Cabe-me apenas segui-lo e esperar que ele termine o meu cativeiro, quando isso lhe aprouver. Seu rosto contraiu. Preciso livrar-me desta idolatria ridícula." (WINSOR, 1987, p. 99).
} 
modo que na primeira solicitação desejante do Diabo ela não Ihe recusará entregar aquilo que ele deseja, isto é, acabará se entregando. Winsor arremata seu raciocínio dizendo que esta dignidade é imprescindível para uma mulher, como salvaguarda de uma sobrevivência decente. Posteriormente examinaremos o que isto significa.

Por hora trabalhemos o desejo que a protagonista padece. Há pouco afirmamos que a temporalidade que vigora no inferno proporciona um tempo livre exacerbado, o que leva a uma liberdade também exacerbada. Esta liberdade, como já analisamos, não necessariamente leva a felicidade, pois não há desejo para se gozar na exata medida em que não há limitações desta mesma liberdade. Porém, uma questão surge agora que buscamos refletir sobre o desejo de Jacinta pelo Diabo: por que despertou-se desejo em Jacinta justamente pelo Diabo? Além do traço geral que o fetichismo assume, chama a atenção também o fato de que a posição do Diabo é privilegiada no mundo em que agora Jacinta habita; ele é o senhor do reino, o indivíduo que ali detém maior poder. Além disso, em consonância com este poder, o desprezo que ele confere a Jacinta parece tãosomente aumentar o desejo desta por ele. Enquanto ainda viva, a protagonista costumava deixar todos os homens aos seus pés graças a sua indiscutível beleza e elegância. Mas, pela primeira vez, sua atração fracassa perante a altivez do Diabo ${ }^{12}$. Assim, o Diabo acaba por ser a única fonte de desejo no inferno, já que nada mais impõe resistência a sua liberdade. Tudo parece à mão, menos aquilo que ela mais deseja.

A autora utiliza termos como "magia", "fascínio", "inclinação", "volúpia", "sentimento persistente" para descrever o que se passava no espírito de Jacinta não apenas quando na presença de seu amado, o Diabo, mas também quando

12 Contudo, como pôde Jacinta esquecer-se do grande amor que sentia por seu amante extraconjugal, Douglas, já no primeiro dia de "estadia" no inferno? Duas razões principais: uma condiz com o fator do desejo irremediável que o Diabo exercia sobre ela; outra diz respeito ao fato temporal de que no inferno esquece-se a vida terrena rapidamente. Embora não seja uma amnésia, as memórias perdem a intensidade e o vigor usual com os quais estamos acostumados. Jacinta mal consegue lembrar-se do rosto de Douglas, mesmo se esforçando para recobrar suas imagens antigas vividas ao seu lado. Em muitos momentos da narrativa a autora expõe que Jacinta se esquece mesmo que esta no inferno e que viveu outra realidade noutros tempos. Para nós, este recurso literário evidencia a tentativa de Winsor em aproximar o contexto do inferno com o de sua época, pois a libertinagem, os hábitos pouco cavalheirescos perante as mulheres, o individualismo, a extrema consideração pela aparência, a rebeldia e a irresponsabilidade que existem no inferno cabem como uma luva naquela moral emergente na década de cinquenta. Voltaremos a esta crítica social posteriormente. 
este já não mais se encontrava fisicamente próximo. Porém, ele sempre estava próximo em pensamentos, dominando a consciência de Jacinta mesmo contra sua vontade. "Parecia que alguma força imperiosa a sujeitava a um desejo estranho e poderoso" (WINSOR, 1987, p. 25). A tentação que ela sofria afetava não somente sua consciência, mas, sobretudo, seu inconsciente. Os desejos conscientes são manejáveis, pode-se executá-los, postergá-los ou abandoná-los. Com os desejos inconscientes não funciona assim: eles são, como a psicanálise ensina, fundados no presente imediato, querem ser realizados a todo custo, aqui e agora seja como for, são desejos implacáveis, quase instintivos.

A narrativa começa a ficar "picante", entretanto, apenas quando Jacinta encontra-se com sua mãe, Cherry. O encontro é aparentemente uma coincidência. Após Jacinta ser encaminhada por um servo do Diabo até o cômodo que passará a eternidade, ela começou a desfazer as malas, bem como a averiguar sua instalação. Algum momento depois Cherry bate em sua porta, solicitando se Jacinta podia the abotoar o vestido na parte de trás. Porém, pensa Cherry, após descobrir que Jacinta é sua filha, é no mínimo suspeito que o dormitório de Jacinta se encontre em frente do dormitório de sua mãe, já que é o Diabo quem determina onde os recém chegados habitantes do inferno vão permanecer acomodados.

Este é um recurso utilizado constantemente por Winston: mostrar que o Diabo não é grosseiro, cruel ou violento em suas maleficências, ao contrário, ele se mostra bastante sutil e perspicaz, ao ponto até do leitor, assim como as personagens, se questionarem se as atitudes tomadas por parte do Diabo são mesmo maleficências. Jacinta responde ao Diabo quando este the pergunta se ele próprio teria feito algo motivador de suas aflições, no que ela reconhece sua não responsabilidade: "É estranho, não é? Você é o causador de tudo e apesar disso não fez nada" (WINSOR, 1987, p. 129). A escritora parece tentar evidenciar como o imaginário feminino produz suas próprias mortificações a partir de pequenas atitudes, gestos, palavras e situações provindas daquele de que se está apaixonada. Coloquialmente diz-se que isto é fazer uma tempestade em um copo d'água.

O encontro entre Jacinta e Cherry é comovente. Porém, logo que Jacinta conta como ficou intrigada (no vulgo brasileiro costuma-se dizer "mexida") com a 
persona do Diabo no primeiro encontro, um temperamento ciumento domina Cherry, pois não é normal que o Diabo vá receber os recém chegados. Geralmente, ele demora muito tempo antes de se apresentar pessoalmente.

O ciúme, no entanto, não parte apenas de Cherry para com Jacinta; também há o ciúme em sentido contrário. Quando ambas desceram até o salão principal, onde incontáveis hospedes se entretinham em conversas acaloradas, as duas mulheres encontraram o Diabo. Ao estabelecerem conversação, Jacinta notou certa intimidade entre ele e Cherry, pois era nítida a troca de olhares e sorrisos entre eles.

Desta querela feminina ${ }^{13}$, aliada ao desejo imponente, surge, ou melhor, revigora-se a vaidade que Jacinta sempre cultivou em vida. Não é uma vaidade simplesmente cotidiana, um embelezamento para si mesma; trata-se mais de um melhoramento conforme a atenção do Diabo. Ela quer despertar o desejo naquele em que seus próprios desejos estão direcionados. É muito comum uma pessoa, tanto do sexo masculino quanto do sexo feminino, principalmente na contemporaneidade, dar importância ao aspecto exterior, à aparência, segundo os olhares dos outros, especialmente daquelas pessoas de que se está enamorado. Mas com Jacinta é diferente porque sua vaidade natural, que Winsor atribui ao gênero feminino em geral como uma forma de poder e proteção, é completamente canalizada à disposição do Diabo. Tamanha é esta subserviência estética que as próprias opiniões de Jacinta sobre si mesma, assim como as opiniões dos outros e de Cherry, sua mãe, já não mais importam quando comparadas com a opinião do Diabo. É neste momento, quando toda a existência, por arrebatamento irresistível, gira em torno de um único eixo diferente de si mesma, que Jacinta se percebe como dependente do reconhecimento do Diabo. Disto surge a questão da autorrepresentação.

\section{AUTORREPRESENTAÇÃO FEMININA}

Pois bem: a problemática central de todo romance é a autorrepresentação feminina. Desde o início até o fim, o que preocupa a autora é retratar como a

${ }^{13}$ Desde este ponto até o fim do romance, o desenlace da estória acontece segundo a tensão passional gerada entre Jacinta e sua mãe. O Diabo, propositalmente, usa artimanhas para inflamar esta tensão, ora cortejando Jacinta, ora Cherry, ora ignorando-as conjuntamente. 
silhueta de uma imagética pessoal de uma jovem mulher é dinamicamente modificada conforme as situações envolvam representações alheias, sejam por parte do sexo feminino (Cherry) ou masculino (Diabo). Inicialmente, está questão aparece destacada no texto quando Jacinta se olha pela primeira vez em frente $o$ espelho de seu novo quarto, admirando sua aparência, trajando apenas um chambre de algodão branco com ornamentos escarlates.

Sem muitas delongas sobre o traje, é interessante notar o jogo contrastante sugerido pela escritora, genialmente expresso numa simples roupa de dormir, entre o pudico e o pecaminoso, entre o casto e o sensual. ${ }^{14}$ Essa ênfase ganha legitimação, conforme o que dissemos anteriormente, segundo os matizes gerais da própria obra, pois é um modus operandi vertebral na narrativa.

Além disso e não menos importante, ao mirar-se no espelho Jacinta, absorta em pensamentos, já se contemplava tendo como pano de fundo de sua autorrepresentação a persona do Diabo, isto é, considerando a representação dele acerca dela que ela mesma projetou (imaginou). "Embora ela anteriormente gostasse mais do que ninguém da própria beleza, no momento apenas se interessava pela reação que despertava no senhor daquele reino" (WINSOR, 1987, p.35). Agora Jacinta olhava-se através dos olhos do Diabo. Estava completamente enfeitiçada pela beleza potente, soberana e convidativa daquele homem ${ }^{15}$. Neste primeiro momento de autorrepresentação influenciada

\footnotetext{
${ }^{14} \mathrm{~A}$ autora parece a todo momento seja de forma direta ou indireta, orientar o leitor aos atributos "exteriores" dos personagens, sem, todavia, abandonar de todo aquelas qualidades ditas "interiores". Em verdade, já esta delimitação tão antagônica entre exterior e interior, assim como a diferenciação entre casto e sensual, é uma confusão muito rotineira na expressão linguística. São poucas as linguagens que buscam superar - num sentido epistemológico - está cisão conceitual. A literatura romântica, como uma expressão eminentemente artística, muitas vezes buscou sobrepujar essa diferença por meio das metáforas e ilustrações, como é neste momento o caso. Afinal, a aparência externa de uma pessoa, como a roupa que traja, não revela algo de seu interior? Uma lingerie de estilo casto não representa, paradoxalmente, muitas vezes uma intenção sensual? Não há contradição nem antagonismo, da mesma forma que não há equiparação necessária: da mesma forma que não podemos dizer com certeza que algo exterior como uma roupa ou um corte de cabelo expressa literalmente uma intenção interna, também não podemos dizer que não seja manifestação do interior. Kathleen Winsor se utiliza constantemente deste recurso, principalmente quando retrata as atitudes de Jacinta como contrárias as suas inclinações internas, como quando a protagonista busca esnobar o Diabo para que ele sinta-se atraído por ela. $O$ ato de esnobar de Jacinta na realidade intima significa outra coisa que propriamente esnobar, significa, paradoxalmente, o contrário. De um ponto de vista realista, tudo isto apenas mostra como as categorizações epistemológicas são estéreis e abstratas quando comparadas com os trejeitos literários.

$15 \mathrm{O}$ fato do Diabo não ser um ser humano não significa necessariamente que não seja, para Jacinta, um homem. Seu corpo, sua voz, seus gestos, sua personalidade... tudo nele é
} 
explicitamente por outrem, Jacinta já buscava na memória recordar as ocasiões em que a sua beleza física assim como a graciosidade de seus gestos cativaram - Diabo, chamaram-Ihe a atenção, a fim de repeti-las quando o reencontro ocorresse. Os dilemas, angústias, receios e preocupações que dessa temática central decorrem aliadas as interferências de Cherry são o corpus essencial do romance.

Apesar do trato rude com que o Diabo se direciona a Jacinta, esta não deixa de querer fazê-lo reparar em seus próprios encantos. Em dado momento, durante uma conversa em que Jacinta incriminava o caráter imoral do Diabo, ele então diz, mudando arbitrariamente de assunto: "Sabe que tem uma boca primorosa? Isto é muito importante para um bastardo mundano como eu", no que ela responde quase fora de si: "Obrigada — murmurando, olhando-o para verificar a reação" (WINSOR, 1987, p. 75). Mesmo Jacinta muito conscientemente tendo noção de que ele representava um canalha, bem como o que ela representava (tanto para a sociedade, para ele e para ela mesma) se sujeitando aquele papel, ainda assim ela esperava ser-Ihe agradável. A escritora coloca seu ponto de vista numa reveladora passagem:

Um dos maiores inconvenientes de ser mulher é ter de esperar. A mulher não pode, como o homem, agarrar o que deseja. É obrigada a gastar a vida seduzindo, adulando, agradando, submetendo-se, iludindo, estimulando, namoriscando; empregando todos os artifícios de que dispõe para atingir suas metas. Até mesmo no inferno isso acontece. (WINSOR, 1987, p. 73).

Esta tensão existente no universo feminino entre o próprio desejo e o próprio orgulho faz com que a mulher sinta-se muitas vezes ansiosa, insegura, irrealizada - especialmente nos casos de amor. ${ }^{16}$ Sem dúvida todos os seres humanos, enquanto coexistem socialmente com outros seres humanos, julgam-se através da maneira como os outros o julgam. Porém, em se tratando de sexualidade, historicamente as mulheres permaneceram com sua liberdade de autodeterminação reduzida a estereótipos muito mais rígidos que os homens.

considerado por ela como extremamente masculino, chegando ao ponto dela considera-lo uma espécie de hiper-homem, ou seja, o mais verdadeiro homem dentre os homens.

${ }^{16}$ A escritora coloca nestes termos esta frustração feminina: "Ele talvez não seja cruel a ponto de divertir-se apenas com as mulheres mais vulneráveis, mas ele próprio disse-me que não se apaixona e eu sei que isso é verdadeiro. Assim é que, mesmo que ele não entretenha mulheres especificamente para torturá-las, é como se agisse dessa forma. Um homem a quem amamos, que não nos pode querer, não pode haver pior tortura." (WINSOR, 1987, p. 99). 
Este agrilhoamento, simultaneamente moral, psicológico e institucional, tem como consequência a maneira imprópria com que a mulher habita seu próprio mundo.

É o que acontece com Jacinta. A protagonista se percebe impropriamente. Seu corpo é belo, caso o Diabo o afirme belo; sua espirituosidade é encantadora, se o Diabo assim o diz; sua vida valor, na medida em que o Diabo a valorize. Sem dúvida preceitos sociais estão ainda em voga no autorrepresentação da protagonista, mas ela, com o decorrer da narrativa, acaba deixando de lado tais preceitos para dar maior importância a opinião geral que o Diabo faz dela ${ }^{17}$.

Neste sentido, e em consonância com o que já dissemos sobre o desejo, a liberdade de Jacinta fica reduzida, limitada e dependente da representação de outrem. Como podemos nos considerar livres, principalmente no contexto feminino, quando não nos percebemos como livres? Daí o empenho contemporâneo das mulheres não apenas por liberdade, mas também por reconhecimento social desta liberdade.

Com vistas neste aspecto social que também a autorrepresentação feminina está inserida, vamos agora identificar alguns momentos da obra da autora em que a perspectiva de seu tempo e dela mesma sobre as mulheres aparecem de maneira evidente. É também uma maneira de autorrepresentação, pois a escritora por ser mulher tem o apanágio legitimo de expressar o significado real de ser-mulher da mulher moderna.

Um dos elementos básicos em que Winsor parece desfilar suas descrições sobre a mulher é o contraste que esta ganha em comparação com o homem. Se entendermos, como a autora sugere, que Jacinta protagoniza a essência da feminilidade assim como o Diabo representa o apogeu da masculinidade, podemos articular uma comparação simultaneamente coerente, impessoal e esclarecedora. Kathleen Winsor descreve Jacinta a partir de uma imagética que sobrepõe a fragilidade pretensamente feminina como característica central, assim como referencia as belezas de seus trejeitos segundo o que elas provocam no público masculino. Já o Diabo é descrito como um ente dominador,

\footnotetext{
17 Esta "não consciência" vai pouco a pouco sendo diminuída por uma tomada de consciência muito alavancada pelas ideias que o Diabo lhe expõe em seus colóquios. O Diabo, como um ser tentador, instiga Jacinta a seguir seus desejos frente seu orgulho próprio. Porém, esta tomada de consciência é paradoxal à medida que ela troca o valor do julgamento social pelo julgamento dele. Podemos pensar aqui em uma manipulação psicológica sofrida pela protagonista.
} 
poderoso, independente, majestoso não apenas por seu aspecto físico, mas, sobretudo, por suas manifestações e gestos ${ }^{18}$. Jacinta, representante das mulheres, é delimitada como um ser vulnerável; o Diabo, representante dos homens, é exposto como um ser invulnerável.

Noutro momento, Winsor (1987, p. 70) aborda a questão da maternidade ${ }^{19}$. Após o Diabo afirmar que separa claramente 0 ato de fazer sexo com o ato de ter um filho, Jacinta se irrita e diz que há separação; diz ainda que se todos os homens pensassem como ele "a mulher tornar-se-ia inútil". Para jacinta, como uma mulher burguesa de meados do século $X X$, a ideia de fazer sexo apenas pelo prazer do momento, sem amor ou intenção familiar, é intragável.

\begin{abstract}
É algo, refletia ela, inacreditável para as mulheres, que o homem, depois de abandonar-lhe o corpo, possa sentir-se totalmente liberto dela. Que possa recuperar-se tão facilmente quanto se entregou. Que possa pensar em si como ente autônomo, sem nenhum vinculo que o ligue à mulher. Enquanto ela é obrigada a ter sempre consigo mesma a certeza de que foi amada. Não há escapatória para ela. (WINSOR, 1987, p. 128).
\end{abstract}

A sexualidade da mulher aparece como reduzida ao laço amoroso. Embora desde pelo menos quatro décadas a libertação sexual feminina tenha sido promovida em grande escala, seja pelas artes (rock'n roll, literatura, filmes), movimentos sociais (hippies, feminismo) ou políticas públicas (educação sexual nas escolas), ainda hoje parece perdurar este estigma que associa intrinsecamente sexo e amor. O aspecto sexual do homem, por outro lado, aparece como independente do amor. Mesmo que o homem possa conciliar amor e sexo, trata-se de uma possibilidade, não de uma necessidade, como é o caso da mulher.

\footnotetext{
${ }^{18}$ Desta maneira é descrita jacinta: "Seus olhos eram grandes e escuros, de expressão a um tempo suave e brilhante. Algo neles denunciava que ela era feita para dar e receber paixão. Esse seu olhar sempre a fez adorada dos homens. Seu semblante era brejeiro e tinha um quê de receptividade. Todos os seus gestos e movimentos eram macios, fáceis, delicados. Ou ela era mulher especialmente talhada para o mais sutis artifícios que encantam e exacerbam a admiração masculina ou era muito versada nos processos de sedução" (WINSOR, 1987, p. 12). Já o Diabo é assim textualmente descrito: "Era uma figura extravagante. Tinha de tudo: força, poderio, arrogância - parecia a própria essência da masculinidade" (WINSOR, 1987, p. 14).

19 O mesmo resultado aparece na comparação entre a maternidade de Jacinta diante da paternidade de Martin, seu marido. Winsor coloca o interesse de Martin como um interesse ligeiro, impessoal, um tanto desinteressado, enquanto Jacinta, aprovando este desinteresse na medida em que Ihe dá espaço para exercer sua maternidade, tem o papel de dar atenção, carinho, ler histórias, participar das brincadeiras.
} 
Enfim, a escritora descreve como a mulher é reconhecidamente vista em sua época. A noção de inferioridade do feminino frente o masculino parece ser um estatuto enrijecido, concreto e natural. Não apenas em sentido social, pois Winsor (1987, p. 126) chega a dizer, por intermédio de Jacinta, as seguintes palavras: "Esquece-se de que as mulheres nascem desfavorecidas. Há algo de ridículo em todas nós. Se não nos protegêssemos, disfarçando nossa deficiência absurda sob o céu de névoa romântica, os homens nos tratariam pior do que tratam". O que é esta deficiência natural, a autora nada diz ${ }^{20}$.

Se tal descrição partisse da pena e tinta de um homem, embora inaceitável, seria ao menos compreensível, já que vivemos em uma sociedade patriarcal dominada por concepções e condutas inegavelmente machistas. Porém como explicar este posicionamento quando ele provém de uma escritora mulher? O fato de a escritora instalar a mulher como o sexo frágil não significa necessariamente nem que a mulher realmente seja mais frágil que o homem nem que a autora concorde com esta instalação. A autora nos parece mais descrever uma compreensão geral da mulher que tanto homens e mulheres testemunham. Jacinta, a protagonista, representa corporalmente e psicologicamente o que significa concretamente ser mulher em meados da década de cinquenta. Desse modo, Winsor quer antes retratar como a mulher se autorreconhece que expor sua opinião própria sobre o assunto.

Por fim, mantendo a modéstia de não concluirmos em absoluto coisa alguma, podemos dizer, segundo nossa interpretação, que o autorretrato feminino esboçado nesta obra por Kathleen Winsor salienta principalmente os aspectos introspectivos e morais que perpassam o drama de ser mulher em um mundo predominantemente regido pelo ponto de vista masculino. A mulher se vê como um ser frágil, carente, e subalterna em relação ao homem; também se percebe como alguém que não deve demonstrar seus desejos sensuais; aparece para si mesma como um ente que tem de buscar na beleza estética o reconhecimento valorativo dos homens e de outras mulheres; reconhece-se, por fim, como uma

\footnotetext{
${ }^{20}$ Freud afirma que a mulher inveja o falo do homem, buscando preencher este sentimento de falta por meio de recalque, sublimação e fetiche. Contudo não podemos simplesmente traduzir este desfavorecimento feminino de que fala nossa escritora com a teoria psicanalítica de Freud. $O$ importante agora é perceber como a mulher é concebida desde uma autorrepresentação negativa que sempre esta relacionada ao homem.
} 
verdadeira mulher somente quando seu comportamento se conforma com o papel de mulher que dela se espera representar.

De tal forma é assim que o autorretrato é constituído, que o assassinato, pelas mãos de seu próprio marido, de uma mulher que teve relações sexuais com outro homem, apesar de já ser casada, se apresenta na consciência feminina como um fim merecido. Apesar do nível reduzido, ainda hoje a mulher vive com consciência de culpa por se comportar livremente no que se refere a sua sexualidade. Mas que este infeliz autorretrato desenhado pela escritora norteamericana sirva de modelo a não ser seguido pelas mulheres de hoje. Que consigam encontrar um modelo de realização pessoal que não dependa preponderantemente do reconhecimento alheio, especialmente do reconhecimento masculino.

\section{CONSIDERAÇÕES FINAIS}

Esperamos, com sinceridade, que não tanto o conteúdo deste artigo tenha chamado atenção do leitor, mas desejamos que o exemplo de um posicionamento, um tanto ousado, que pretende extrair signos filosóficos das entrelinhas de um romance comum tenha despertado sua reflexão. Esta atitude de aquecer o pensamento é a finalidade última de uma interpretação filosófica despertar e preparar a consciência crítica para ir além de leituras superficiais. Não são só os Shakespeare, Goethe, Dostoievski ou Kafka que podem ser aprofundados; qualquer texto, por mais simplória que seja sua linguagem e estilo, pode ser analisado criticamente e terá muito a ensinar para aquele que não tem preconceitos.

Enquanto uma leitura filosófica, não cabe a nós responder as inúmeras questões aludidas no decorrer da obra da escritora estadunidense; nem tampouco as questões que surgiram neste texto. Cabe-nos antes a tarefa de levantar e problematizar estas questões de modo que o leitor se interesse em buscar por conta própria um aprofundamento. Muitos textos tidos como superficiais por não serem meramente acadêmicos albergam em seu escopo uma potência criativa que muitas vezes passa despercebida pela crítica. 
No caso do romance Jornada Diabólica, a tematização ficcional de uma intriga amorosa que se passa no inferno nos revelou-se com uma significação e complexidade maior que uma corriqueira leitura passatempo. É a ambiguidade, que simultaneamente esconde e revela a importância dos temas trabalhados na estória, produzida pela literatura romanceada, que buscamos senão decifrar ao menos iluminar pela atitude filosófica ${ }^{21}$. Essa função pragmática da literatura também está presente no romance Jornada Diabólica. Sem qualquer sistematização conceitual, a escritora Kathleen Winsor conseguiu mostrar, a partir de uma estória de ficção fantástica, senão suficientemente ao menos inteligivelmente o que significa ser mulher na prática. Oxalá a forma como a mulher lida com seu próprio tempo, seus próprios desejos e sua própria autorrepresentação se constitua cada vez mais de forma livre e frutificante. É preciso ter em mente tudo isso - o talento crítico de escritoras de romances como Winsor, o papel que se espera da mulher pela sociedade, o posicionamento que o amor e a sexualidade têm no mundo feminino, as possibilidades de autônoma reconfiguração social — em um tempo que permite e atua por meio de revoluções cotidianas.

\title{
FEMALE AUTHORRETRATE: A PHILOSOPHICAL READING OF NOVEL "DIABOLIC JOURNEY"
}

\begin{abstract}
Today the social significance of women has been are all the world a theme for uncountable literary expositions, from academic works to marginal poetry. However, we think there is a niche ignored about the theme: it is the romanticized literature, scarcely highlighted by literary criticism, still unknown to the public and develops the plot about woman or femininity as the central theme. More, it is this literature preferentially according to production by women writers. The object of this article is the novel of the American writer Kathleen Winsor titled Diabolic Journey, where presents the feminine world of the century XX by means of fictional narrative. The way we approach this will be guided, with the help of some contemporary thinkers, by the philosophical
\end{abstract}

\footnotetext{
${ }^{21} \mathrm{E}$ talvez seja por essa maneira mais furtiva, alusiva, indicativa, imprecisa que esta ambiguidade seja mais compreensível aos leitores de um romance que aos leitores de tratados técnicos. Esta maneira superficial de abordar um assunto permite a apropriação deste mesmo assunto de forma mais imediata (propriamente significativa) que numa linguagem vertical. É o que alude o filósofo alemão Hans Blumenberg (1920-1996) em seu livro Teoria da não conceitualidade. Nesta obra o autor diz que a metáfora se distingue fundamentalmente do conceito porque está enraizado no mundo da vida [lebenswelt], a única região em que faz sentido. Já o conceito é um distanciamento racional deste mesmo mundo da vida, porém sem haver uma ruptura, de maneira que o conceito é uma espécie de abstração metafórica do real. A literatura romanceada, por estar mais próximo da região metafórica, tende a estar mais próxima do mundo da vida. Esta pode ser a maior significação de importância que a literatura pode oferecer: a aproximação indireta do leitor ao real sentido do mundo em que vive.
} 
interpretation of the component points of the novel, can be synthesized as a love triangle happens in hell. The fantastic character of the plot does not negate or empty the realistic sense that the being-woman is worked on by the author; the contrary, the metaphorization establishes hell as the region where everything happens represents a literary artifice that brings the idea of hell to the real context. In other words, between earthly reality and hell there are many similarities regarding to role of women. The objective of this text is develop by the philosophical argumentation the verticalization of a seemingly unimportant work, thus demonstrating that even the little expression fantastic literature has much to contribute on current themes, as is the question of women's social performance.

KEYWORDS: Philosophy. Fantastic Literature. Interdisciplinarity. Winsor. Women.

\section{REFERÊNCIAS}

MEIRELES, Cecília. Precursoras brasileiras. In: MEIRELES, Cecília. Crônicas de Viagem I. - 3ª edição - Rio de Janeiro: Editora Nova Fronteira, 1998, pág. 227229.

SCHOTT, Robin. Eros e os Processos Cognitivos: uma crítica da objetividade em filosofia. - Tradução de Nathanael C. Caixeiro - Rio de Janeiro: Ed. Rosa dos Tempos, 1996.

WINSOR, Kathleen. Jornada Diabólica. In: WINSOR, Kathleen. As Amorosas. Tradução de Gilberto Bernardes de Oliveira - São Paulo: Nova Cultural, 1987, pág. 9-185.

Data da Submissão: 10/04/2018

Data da Aprovação: 24/07/2018

Revista de Letras JUÇARA, Caxias - Maranhão, v. 02, n. 01, p. 224 - 243, jul. 2018| 243 